\begin{tabular}{|c|l|}
\hline Title & Environmental restoration of Minamata: new thinking brings new advances \\
\hline Author(s) & Yoshida, Fumikazu \\
\hline Citation & $\begin{array}{l}\text { Sustainability Science, 2(1), 85-93 } \\
\text { https:/doi.org/10.1007/311625-006-0017-2 }\end{array}$ \\
\hline Issue Date & 2007-04 \\
\hline Doc URL & http://hdl.handle.net/2115/53272 \\
\hline Rights & The final publication is available at www.springerlink.com \\
\hline Type & article (author version) \\
\hline File Information & yoshidaSS.pdf \\
\hline
\end{tabular}

Instructions for use 
OVERVIEW ARTICLE

\title{
Environmental restoration of Minamata: new thinking brings new
}

\section{advances}

\section{Fumikazu Yoshida}

\begin{abstract}
This paper discusses the idea of environmental restoration and the creation of sustainable cities of industry and culture by spotlighting how the city of Minamata, Japan, which was severely affected by environmental damage, is rejuvenating itself by means of a unique strategy based on a new way of thinking and the fostering of human resources. Taking its lead from the concept of environmental capacity building, this paper focuses on environmental restoration as (1) a mending process for the social environment and human relationships, (2) a strategy of actor participation, particularly citizen participation, in environmental restoration, and (3) a role for human resource development.
\end{abstract}

Keywords Minamata _ Environmental restoration_Sustainable city

\section{Introduction: an attempt at creating a sustainable city of industry and culture in Minamata}

What is now known as Minamata disease was officially recognized 50 years ago; with the Minamata disease incident as background, this paper will discuss environmental restoration and the creation of sustainable cities of industry and culture by focusing upon how the city of Minamata, Japan, which was severely affected by environmental damage, is rejuvenating itself by means of a unique strategy based on a new way of thinking and the fostering of human resources.

This paper analyzes the experience from the perspectives of environmental capacity building and environmental governance, and explores the possibilities of the application of such principles in other countries. When considering environmental capacity building, it is important to incorporate the concept of the actors involved, who approach environmental problems from many different standpoints. Actors are the parties, such as government agencies, private enterprises, local citizens, and the media, that are concerned with a given problem. They are called actors because they approach a problem with their own individual interests and risk awareness, on the basis of which they develop and implement their own individual strategy. Actor awareness and related actions are limited by the framework conditions imposed by the social system. These include (1) conditions pertaining to cognizance and information, (2) conditions imposed by the political system, and (3) economic and technological conditions. It is under these conditions that actors face situative opportunities (real-world conditions), using the strategies, intentions, and skills they have to deal with them. Important here are the type and urgency of the particular environmental problem and the mutual relationships among the actors (Ja“nicke2002). By regarding environmental politics as an arena peopled by actors with differing standpoints, we see a 
situation where actors build the social system and the dynamic of interaction among themselves, instead of a situation where the social system arbitrarily defines the actors' functions.

Working with the concept of environmental capacity building, this paper will focus on environmental restoration as (1) a mending process for the social environment and human relationships, (2) a strategy of actor participation, particularly citizen participation, in environmental restoration, and (3) a role for human resource development.

This paper will discuss the following topics: (1) a brief history of Minamata disease, its causes and effects, (2) consequent environmental restoration efforts and initiatives, (3) the environmental city: providing for livelihoods, and (4) environmental initiatives for industry revitalization.

\section{Minamata disease: a brief history}

What is Minamata disease?

The ingestion of fish and shellfish polluted by methyl mercury causes what has come to be known as Minamata disease. In the incident that gave its name to the disease, the Chisso chemical company in Minamata City, Kumamoto Prefecture, southern Kyushu, was responsible for the methyl mercury pollution, which was generated by catalytic reactions in the production of acetic acid. The disease brought about many nervous system disorders, mostly among fishermen. In 1956 the disease was officially recognized, and researchers from Kumamoto University Medical School demonstrated that factory effluent was the pollution source; the factory denied this, however, and it was not until 1968 that the Japanese government acknowledged the factory as the source. By that time the pollution and damage had spread considerably (Harada 1972). The main reason that the response to Minamata disease was delayed for so long was that the government, which was responsible for solving the problem, lacked environmental capacity (i.e., it had no authority for policy coordination and integration). There was, as yet, no government agency like the present Environment Ministry to deal with the disease as an environmental problem. Moreover, due to the compartmentalized isolation of government ministries and agencies, the Economic Planning Agency, which should have taken the lead in remedial measures while providing for policy integration that transcended individual government agencies, could not perform that role because the government agencies were divided by bureaucratic sectionalism. It was the Ministry of International Trade and Industry (MITI) that was actually in control, and it provided, with a clearly risk-aware, pro-industry strategy, intensive guidance to the factories over which it presided. Although the Ministry of Health and Welfare (MHW) took the lead in solving the problem at the outset, it gave way to pressure from MITI and avoided making political decisions that would adversely affect the chemical industry (Yoshida and Yoshida 2004).

The strategy adopted by MITI and industry, of delaying the determination of the cause of Minamata disease and avoiding repercussions for the chemical industry, resulted in an outbreak of Minamata disease in Niigata Prefecture in 1965. While it appeared that Japan's industries had successfully avoided mercury 
regulation and the banning of factory effluent, which were the immediate risks to the chemical industry, this resulted in widening the environmental risk. Minamata disease was not the only environmental problem facing Japan at the time. In addition to "itai-itai” disease, which was caused by cadmium poisoning from mining pollution, the petrochemical complexes around the nation, which were regarded as the new hope of the chemical industry, were responsible for serious air pollution, as evidenced by “Yokkaichi asthma.” This represented a strategy failure for the chemical industry, as well as for MITI and its policy of giving precedence to mining and manufacturing profits over the health of the Japanese people. Thus, it also represented a failure of the government's policy for rapid economic growth. In 1968, the MHW was obliged to take over the responsibility of acknowledging the source of Kumamoto Minamata disease in place of the Economic Planning Agency.

Minamata disease was officially confirmed as a disease in 1956. As of January, 2006, the government had officially certified 2,265 patients, of whom 707 survive, and the so-called "'government solution measures”' of 1996 cover 11,148 people living in Minamata City, Izumi City in the adjoining Kagoshima Prefecture, and other areas (8,333 survivors). However, since the 2004 Supreme Court decision that finalized recognition of the responsibility of the national government and Kumamoto Prefecture, about 4,000 more people have filed applications for certification as Minamata disease patients, so that the total number of patients has yet to be ascertained.

According to our earlier study (Sugiura and Yoshida, manuscript in preparation), under the government measures of 1996, eligible persons were issued with patient IDs and received medical treatment allowances. In actuality, these allowances served both as a way of providing health examinations and as a way of encouraging patients to visit healthcare providers in order to gain qualification for the allowances. For that reason the government's measures have played a major role in the recovery of physical and social functions by enabling people to receive medical care and medical advice. However, relief programs under the government measures accepted applications only in 1995 and 1996 and covered only patients whose applications were approved. There were also people who avoided applying because of Minamata disease discrimination, as well as those whose applications were turned down. Those people are presumably unable to benefit from the programs.

\section{Chisso today}

Chisso Corporation is now based in Tokyo but has factories in Minamata and in Chiba Prefecture. After the petrochemical plant in Chiba was completed, the Minamata factory accounted for roughly $20 \%$ of total sales, but when its petrochemical business later became uncompetitive, the company began to focus on organic synthetic chemistry and has, in recent years, increased its sales of both " fine” and "functional" chemicals, which are regarded as promising fields and now account for about $80 \%$ of the Minamata factory's sales. Chisso's work in liquid crystal materials, especially TFT, which began in 1978, accounts for nearly half of the world market. The company also has 13 hydroelectric power stations and 
sells clean energy. Its longtime fertilizer factory is turning into a high-tech plant, and there are no plans to leave Minamata as a consequence of consolidation. Having learned its lesson from Minamata disease, Chisso linked up with Minamata City in 2001 for ISO 14001 certification and a Responsible Care program, and its new employees all receive training at the Minamata factory.

As the company that caused Minamata disease, Chisso shoulders a huge liability for compensation. Beginning in 1975, the company's financial fortunes took a dip, raising concerns that it could no longer pay compensation, so from 1978 to 2000 Kumamoto Prefecture floated prefectural bonds to support Chisso financially (the total loan is about $¥ 260$ billion). Owing to Chisso’s repayment difficulties, however, the prefecture granted an extension beginning in February 2000, during which time the national government would make payments every year in place of Chisso. The idea is that the government is supporting Chisso under the premise that the "polluter pays" principle is not jeopardized, and is, in effect, preventing the economic blow that would befall Minamata should Chisso go bankrupt.

In March 2006 Chisso earned $¥ 16.9$ billion of normal profit, thanks to the increasing sales of liquid crystal materials for TV. If this situation continues, the possibility of Chisso's paying back its debt within 10 years will be realized. Uncertainty remains, however. The success or failure of Chisso will deeply affect the socio-economy of Minamata.

\section{Environmental restoration efforts and initiatives}

This section discusses the process of mending the social environment and human relationships as a form of environmental capacity building.

\section{What was lost due to Minamata disease}

Harm from the Minamata disease incident, which has lasted for half a century, is not limited just to sufferers of the disease. Harm to the region itself, and the antagonisms that arose among its inhabitants, is also grave. In order to get the local economy back on its feet by means of environmental restoration, Minamata City has had to provide redress to Minamata disease sufferers and recover from a decline in its fisheries, a population exodus, rumor-induced damage, and other deleterious effects.

In terms of human resources, Minamata City suffered industrial decline and population loss while Japan, as a whole, was enjoying unprecedented economic growth. Post-war acceptance of repatriates from Korea (many of whom were originally from Minamata) swelled the city's population to its highest level of about 50,000 in 1955, while, during the decade from 1965 to 1975, the population decreased by about 10,000 to 36,000. It recovered slightly in 1980, but the decline continued, and, by 2004, Minamata had 30,000 people. During these years, the average income in Minamata fell from the second highest in the prefecture (after Kumamoto City) to the lowest (Miyamoto 1977).

The Minamata disease issue and Chisso's economic fortunes heavily influenced Minamata's economy. There is a close correspondence between the city's population and the number of Chisso employees. 
Minamata disease and the decline of fisheries, Chisso’s labor disputes (workers' struggles for stable wages), the conversion to petrochemical manufacturing, and other factors underlay Minamata's population exodus during the years of rapid economic growth.

\section{Rumor-induced damage and mutual antagonism}

Another problem is the damage caused by rumors and the consequent development of antagonistic feelings among the inhabitants. After its official recognition in 1956, Minamata disease was termed a “communicable disease." Once this rumor spread, it could not be quelled, and it damaged not only the sufferers but the entire region. This damage occurred because administrative authorities neglected to inform everyone in Minamata and elsewhere that Minamata disease was not contagious; hence, it represents a policy failure of the central and local government actors. There were many instances in which marriage arrangements were broken off and jobs were lost not just because of discrimination and prejudice against sufferers of the disease, but simply because someone was born in Minamata. Those who left Minamata did all they could to hide their origins. The Japanese public avoided processed primary industry products from Minamata, fewer tourists visited, and all Minamatans found themselves in difficult circumstances. The anger of Minamatans at suffering unexpected indirect harm was directed at the sufferers who applied for certification as patients. Those sufferers were criticized for causing the situation by claiming to be Minamata disease patients in order to get money. Hate and jealousy spread, causing the disease sufferers to suffer in four ways: social discrimination, illness, poverty, and isolation. In addition to this rumor-induced damage, the Minamata disease issue generated much deep antagonism among the actors. Arising first of all between the polluter Chisso and the people who developed Minamata disease, hostility subsequently grew within the community itself, among Minamata disease sufferers because of different levels of compensation, and between sufferers and non-sufferers, sufferers and administrative authorities, and the public and supporters of the sufferers. This was a result of Minamata's dependency on Chisso in all spheres of life, including politics and economics, and because the city had previously prospered because of Chisso. That the company in this company town was the polluter induced conflicts among many interests in the parochial society that had grown up around the company. Many negative descriptive terms come to mind, such as prejudice, discrimination, criticism, slander, backlash, enmity, struggle, self-depreciation, envy, and ostracism; Minamata became a chaotic society where all of these applied (Yoshii 2003).

\section{The initiative of the prefectural government}

One environmental and social restoration initiative has come from the prefectural government actor. In 1990, on the occasion of more or less finishing a landfill site for dangerous mercury-laden sludge from Minamata Bay, Kumamoto Prefecture created the “'Minamata Redevelopment Promotion Office” and set to work on an ambitious initiative to rehabilitate the city. The officer in charge went to Minamata every 
week. He talked with sufferers and Minamatans in general to determine the structure of the local community. In 1993, after a series of course corrections, the office issued “A Blueprint for Minamata Restoration."

This document made clear that the Minamata disease issue consisted of a connection between the malady, the state of Minamata Bay, and human relationships in the local community, and it spoke of the need to "build a community consensus" and "eliminate the image of a shunned locality."

The fundamental strategy for the environmental restoration of Minamata was:

1. to eliminate its dependence on Chisso

2. to diversify its industrial structure

3. to create a model environmental city through a vision of broad reconciliation

4. to find a solution to the problem of redress for sufferers

5. to ensure the safety of Minamata Bay

6. to redevelop the city into one where the environment, health, and citizen welfare are considered important, based on mutual understanding among Minamatans

Stimulated to a new awareness by these prefectural efforts and initiatives, Minamatans themselves started to act. It was the beginning of a "new partnership” movement for a reawakened awareness among citizens, a movement with the following objectives: (1) since diverse values have emerged from pollutiongenerated antagonism, let us recognize all such values; (2) let us develop the ability to listen to opinions and rationales that differ from our own; (3) let us lower our fences, engage in dialogue, and create a common set of values for new community development.

\section{The environmental city: providing for livelihoods}

This section analyzes the strategy of actor participation, in particular citizen participation in environmental restoration, as a mode of capacity building.

\section{The "new partnership" movement and citizen participation}

Masazumi Yoshii, who became mayor of Minamata City in February 1994, came from a forestry family in the mountainous area of Kukino (in Minamata those in forestry are called "mountain people" as opposed to fishers or "'sea people"). He had no direct past connection with Minamata disease and was, therefore, in a position to analyze the problems facing the Minamata area objectively. Yoshii believed that solving the problem of redress for Minamata disease first required eliminating the antagonism that had arisen between the sufferers and the authorities. Therefore, just after he assumed office, on May 1, 1994, he held a memorial ceremony for Minamata disease sufferers, attended by dignitaries including the director-general of the Environment Agency and the governor of Kumamoto Prefecture, at which Yoshii delivered a message of contrition and apology and stated that the city's past actions on Minamata disease had been mistaken. Even the various sufferers' groups, which had been split until then, agreed on this 
approach of "reaching a quick solution through dialogue."

Strategically, this new approach allowed administrative authorities to change the course of events from antagonism to cooperation through contrition and apology and converted a detrimental legacy into a positive asset; furthermore, a focus on environmental restoration allowed Minamatans to regain their selfconfidence and pride. That led the community to work on rediscovering human and other resources through a "new partnership" that aimed to repair social relationships.

Realizing that the new partnership would require ample opportunities for many Minamatans to meet, and plenty of venues where they could talk, the city held a variety of events, including teach-ins, public lectures, dialogue meetings, and international conferences. Minamata also established a city administration that allowed considerable citizen participation, making dialogue possible between the general public and the Minamata disease patients, who would all have had very different viewpoints. In 1996, Mayor Yoshii formulated the Third Comprehensive Plan, an overall plan for the city, as developed by its citizens. This made Minamata the first municipality in the country to develop a future image as a sustainable city of industry and culture working toward environmental restoration and industrial rejuvenation, accomplishing this through citizen participation in a "'new partnership.” Initiatives implemented under the plan were all noteworthy as means of encouraging citizen participation. These included the formulation of the Third Comprehensive Plan through the Minamata 21 Plan Citizens Conference (1994) and the 21st Century Minamata Citizens Conference (2000; both conferences actively enlisted citizen participation), letters to the mayor (1,400 received between 1994 and 2000), and informal local meetings with the mayor (4,200 participants over the same period). The Third Comprehensive Plan's vision for Minamata's future was of “a city of industry and culture that values the environment, health, and welfare.' It set forth six basic elements: (1) resolving the Minamata disease issue and restoring and reshaping the environment, (2) creating working environments in which people can coexist with nature, (3) creating people-friendly livelihoods, (4) creating a vigorous and vibrant community, (5) creating a Minamata culture, and (6) developing the community with citizen participation.

\section{Practical action to create a model environmental city}

Minamata's recycling industry is regarded as a prototype for a model environmental city. This industry is deeply connected with the citizens' recycling activities.

\section{Separate collection and recycling}

Since 1993, Minamata residents have, as prime actors, sorted their trash into 21 categories in an effort to recycle the city’s municipal solid waste (MSW). This “21-sorting”" system is a pioneering achievement and the most advanced trash sorting system in Japan. This initiative arose from a city proposal and after much debate among Minamatans. Combustible waste is collected twice a week, but, in addition, once a month the citizens cooperate in sorting recyclable materials that single people, the elderly, and others in 
their neighborhoods find difficult to manage. Part of a larger effort to revive local communities, these “trash bin gatherings" have become very popular. People can learn a great deal through trash-sorting activities. Each year the sale of recyclable materials earns between $¥ 5$ million and $¥ 6$ million, which is given to the city's 26 administrative districts to install street lights, finance sports events, and for other uses. Kitchen waste is collected twice weekly, composted, and used in the cultivation of salad onions, which are a specialty of Minamata.

\section{The Women's Waste Reduction Council}

In an effort to gain ISO 14001 certification, Minamata City called on its citizens to generate less waste. In response, the Women's Waste Reduction Council was set up with the participation of over 3,000 women from 16 Minamata women's organizations concerned about waste. In an attempt to keep items that become waste from entering the home, the Council held talks with large supermarkets about discontinuing foam trays and entered into agreements with stores to discontinue trays for certain goods. As a result, the stores themselves say they are saving on packaging costs. Also, when the city grants “ecoshop" certification to stores that take pains to conserve resources and reduce waste, it is the WWR Council that performs the review.

\section{Eco-friendly community development}

To rebuild communities bitterly divided by Minamata disease, “Coming Together Groups” were formed in 26 areas of the city in an attempt to achieve this through joint local government-citizen action, and “community resource maps”' were created. Rather than being a wish-list for something that does not exist, these maps were meant to pinpoint existing local resources and develop them. This involved rediscovering local resources such as eels and crabs in rivers, plant resources in the mountains, fish and other marine resources, and large, old trees, all of which were placed on a single picture map. The maps were an attempt to help people reassess their local environment through their own efforts. Similar efforts included the creation of water channel maps to investigate the use of local water resources.

\section{Environmental initiatives for industry revitalization}

Initiatives have also been taken that aim to revitalize industry in order to establish a firm economic base by building on the foundation of a livelihood-first environmental city, as already described.

Manufacturing has always formed the core of Minamata's urban industry, and, under the Third Minamata City Comprehensive Plan, the city of industry and culture concept was conceived as working toward advancement from primary to tertiary industries while maintaining a balance from the working person's point of view. This section explores trends in a variety of fields associated with the transformation of pre-existing industry: a new recycling industry, environmentally friendly agriculture and fisheries, eco-tourism, healthcare, and human welfare, focusing on strategy and human resources development. 


\section{The eco-town strategy}

\section{Putting recycling into practice}

Minamata City planned to rebuild its industry by offering itself as a center for the concentration of recycling initiatives, and, after 4 years of effort, it received approval as an “Eco-town'” from the Ministry of Economy, Trade and Industry and the Ministry of the Environment. It was the 13th such city in Japan and the first small city to be so approved. The Eco-town project is a government model project, launched in 1997 to promote pioneering eco-friendly community development.

Why did Minamata wish to be a center for recycling industries? It is probably because environmental conservation activities and cyclical industries are the two most vital elements for building environmental cities. Minamata has a common destiny with Chisso; it flourished when Chisso prospered and was devastated by Chisso's pollution. Having learned its lesson from this, Minamata was aware of the need to create an industrial safety net by attracting a wide variety of companies to prevent the sort of harm that arises from dependence on a single company. Additionally, the trash-sorting system practiced by Minamatans is now in the national spotlight and has been highly praised. Minamata City therefore wanted to couple recycling industries with waste sorting and to transform conservation activities into operations that would be seen as economically positive. Minamata is turning itself into a locus of environmental learning, and the idea is to have its recycling facilities as places where the cycling of resources can be observed. Ideally, waste should be recycled at or near the place where it is generated. Moreover, things that can be recycled in simple processes create the lowest environmental burden. Accordingly, Minamata aimed to become a model for small and medium-sized cities by bringing together recycling facilities in a fashion unique to Minamata.

Seven facilities are already sited in the Minamata Industrial Park (Recycling Center), which was built on a 20 ha brownfield site. Total investment in the center, which employs roughly 120 people, was approximately $¥ 6$ billion. The park has a total of 37 sections on 15 ha, of which 32 sections on 14 ha have been leased.

Among these facilities are:

(a) Act-be Recycling, a consumer appliance-recycling facility (49 employees, 12 seasonal workers)

(b) Tanaka Company, a glass-bottle reuse and recycling facility (11 employees)

(c) RBS, a fertilizer-manufacturing facility using sewage and other materials (six employees)

(d) Replatech, a facility where waste plastic is recycled into compounded reconstituted resin (24 employees)

\section{Waste disposal site issues}

Since Minamata already has a large mercury-laced sludge landfill site, the construction of further industrial waste disposal sites is currently a much-debated topic in Minamata, because IWD Toa 
Kumamoto (a subsidiary of Toa Road Kogyo Co., Ltd.) plans to build final disposal sites (controlled and least-controlled) in the Nagasaki-Kiusuno area of Minamata City. These sites will be prepared to accept industrial waste from all over Kyushu. As the sites are located upstream from Minamata City’s drinking water source, which comes through the Yudegawa River system, a citizens’ movement to protect Minamata's water source has arisen. The campaign includes a petition drive that has garnered signatures from $80 \%$ residents of this area in Minamata City. The governor of Kumamoto Prefecture has taken a position favoring environmental conservation and has made stern comments on the proposed dumpsite construction.

In the spring 2006 mayoral election, Katsuaki Miyamoto, who strongly opposes the waste disposal sites, was elected. The reasons were: (1) the sites are located upstream near the city's drinking water source, (2) Minamata has a special history and already houses the mercury-waste dumpsite, and (3) the site location runs counter to the waste reduction initiative. Miyamoto set up a special section of the city government dealing with the waste disposal sites. In June 2006 a special campaign rally (drawing 1,200 people) against site construction was held. How Minamata City as a whole deals with the issue will be a test case of how to become an environment-friendly and economically sustainable city.

\section{Environmentally friendly agriculture and fisheries}

The Minamata region along the Minamata River watershed is a land of green terraced rice fields fed in the summer by copious spring water, with a coastline bordering fields of mandarin trees whose branches hang heavily laden with fruit in the fall and winter, while the Shiranui Sea glows in the evening sun. This region contains a complete ecosystem composed of the sea, a river, and mountains. The watershed's ecosystem is indeed a microcosm of Japan's natural features.

\section{“Minamata brand” agricultural produce}

Because of the Minamata disease scandal, Japanese consumers began to shun agricultural and fishery products from Minamata. However, citrus horticulture has always flourished in the region, and a local specialty is a type of quickly maturing salad onion that can be eaten raw. When consumers began to ask whether produce from Minamata was safe to eat, producers responded to these concerns by changing the way they grow produce, being quicker than other regions to reduce chemical fertilizer use by $70 \%$ and eliminate spraying. Producer understanding was obtained from the Minamata disease experience. Produce is grown early in the year while there are still few insect pests, so it is not just a matter of being “'organic,'” which does not in itself guarantee that production will go well. The local producers also established a production center and made it possible for elderly farmers to produce as well.

Success was not due to initiatives by the local agricultural cooperative alone: all Minamatans contributed, thanks to the linking of these initiatives with community development. At the same time, producers benefited from the publicity that brought people from Tokyo because of the Minamata disease 
issue; hence, success was realized because the environment was emphasized from the outset. Chisso cooperated by providing special fertilizer.

\section{An eco-conscious fishing industry}

From the 1970s until the removal in 1997 of partition nets that had been extended across Minamata Bay to prevent the catching of contaminated fish, Minamata paid fishing cooperative members about $¥ 1$ million in annual compensation, but this came to an end when the nets were removed and fishing as an occupation was revived. New people joined the cooperative. Technical innovations in fishing methods advanced in the 1990s, and fishing for baby sardines also happened to flourish at this time, enough to allow some fishermen to make a living from it. Furthermore, the popularity of fishing has given rise to a population of "part-time fishers" who work at other jobs at the same time. Some elderly fishers have found young men to take over their operations, and there are a growing number of families who make a living by combining fishing for baby sardines with the cultivation of citrus. For example, in Modo, a district with many Minamata disease sufferers, a group of about 20 people work four boats and seek to achieve sustainable fishing. Many Minamatans, including those who have returned from large cities, are trying to produce safe foods, such as dried sardines with no artificial preservatives and citrus fruit with no pesticides.

\section{Eco-tourism}

Minamata's eco-tourism is unique in that it informs visitors about the Minamata disease experience and tells them about the city's efforts to become an environmental city. These two purposes have been melded and made into two programs. One is an environmental study program with a diverse range of courses for elementary, middle, and high school students. The "Learn from Minamata Disease”' course includes such features as listening to a recorded recital at the Minamata Disease Archive, visiting places of significance to Minamata disease, such as the factory effluent outlet, and talking with sufferers of congenital Minamata disease. The “Thinking About the Environment”' course involves learning about Minamata's 21-category waste sorting efforts and visiting a recycling plant.

A non-profit organization (NPO) called Minamata Educational Travel Planning coordinates these ecotours. In an attempt to change the detrimental legacy of Minamata disease into a future resource, i.e., that of an environmental city, the NPO organizes recycling companies, farmers, fishers, Minamata disease patients, and volunteer guides, as well as hotels, tourism businesses, and others, into a network and is looking for a way to orient them as environmental businesses. Pains are taken so that visitors are not just passive tourists but come to learn as at an eco-tour destination resort, where combining programs with advanced classes and training raises the level of environmental learning.

\section{Healthcare and welfare challenges}


Minamata City must not only care for its Minamata disease patients but also look after the elderly, since it has a very high aging rate, with $27 \%$ of the population aged 65 years or older and a growing number of elderly people living alone. Indeed, Minamata has a higher population-to-facility ratio for healthcare and welfare facilities than most other cities, but it remains to be seen how it will adapt a healthcare and welfare system initially built to cope with Minamata disease to serve as a welfare system for an aging society.

A facility that deserves special attention from the perspective of giving full play to the independence and autonomy of the handicapped, instead of merely providing welfare, is "Hotto House," a workshop for people with congenital Minamata disease. With the goal of helping the handicapped find meaning in life by becoming members of society through work with broad social ties, Hotto House was founded in 1998 as a small commuter-type employment facility. At the end of 2003 it became a social welfare corporation. Hotto House conducts three types of activity with social and economic significance, functioning as a place where people with congenital Minamata disease and the handicapped can mix with the public, as a place where anyone can participate, regardless of the type and/or severity of their handicaps, and as a place that is open to the community. Visitors first enter the tea-shop and product sales section, the purpose of which is to encourage workers to interact with the public. This section also sets out tables at city events, instead of confining itself to Hotto House. Second is the work section, where people make pressed flower products (such as bookmarks, coasters, and business cards) and lavender pot pourris using wild flowers that symbolize the richness of Minamata's natural environment. They also make and sell bread at the Minamata City Hall and high school. Third, in activities designed to tell the public about the Minamata disease issue, Hotto House members create programs combining their own experiences and narratives, songs and readings, photographs, and other elements, and take these programs to the public by conducting classes at schools or by taking high school students along on educational trips.

In addition to handicapped people that do not suffer from Minamata disease, Hotto House now has ten members and two full-time employees, as well as a number of citizen volunteers who also work there. The hope is that, instead of leading isolated lives, the handicapped will be able to show how they are living respectably in a way that allows them to find worth in their lives. It is hoped that Hotto House can become a live-in facility in the near future.

These activities form the basis of a proposal to designate Minamata and its neighboring area as an “Advanced Model Environment and Welfare Area” authorized to carry out comprehensive policies and create an area where congenital sufferers will be able to live comfortably (Discussion Group on Minamata Disease, Ministry of the Environment 2006). In response to this proposal, in September 2006, the Environment Ministry opened a special section for promoting a model environment and proper welfare in Minamata and neighboring areas while cooperating with related cities.

\section{Conclusion}


Minamata is known around the world as a result of the haunting black-and-white photographs of the polluted sea and Minamata disease sufferers. Indeed, polluted environments do not easily recover, and the Minamata Bay landfill site still contains mercury-laced sludge. There are still sufferers who have not found redress, even after the 1996 political settlement. In particular, as a consequence of the Supreme Court decision in 2004 acknowledging government responsibility for Minamata disease, over 4,000 people are now applying for certification. An agenda to set up a permanent scheme for relieving and compensating all sufferers without exception remains an urgent necessity.

Nevertheless, the time has clearly come to give the world a full-color picture of the flourishing people and natural environment of Minamata. We must present an image of Minamata that shows it taking steps toward changing the mechanism that led to Minamata disease while at the same time working actively for true environmental restoration.

To inaugurate strategies that take advantage of cities as resources is the key to eliciting, through the example of Minamata City, a widely applicable lesson for rejuvenating industrial cities by transforming them from sources of pollution into cities that are examples of sustainable industry and culture.

Minamata’s successful strategy of carrying out capacity building for environmental restoration can be generalized as follows.

The initial step is to mend and rebuild the social environment and human relationships, because environmental estoration does not simply mean remediating a polluted environment. In Minamata’s case the severity of the problem of mushrooming antagonism among the actors meant that there was an extraordinary need to restore relationships between citizen actors and government authorities. This is closely related to the framework condition of cognizance of and information about capacity building. Here is where one finds the significance of the "new partnership" movement, and it is essential to have a readiness to listen to what pollution sufferers and other perceived as the weak in society are saying, and to find social redress for them. This could be seen as taking the form of a public debate on environmental justice, and it requires the means to enable debate and to plan development with full citizen participation. The second requirement is a strategy, with full citizen participation, for changing conventional ways of thinking and for transforming liabilities into assets. It is a strategy intended to transform the detrimental legacy of being known as a polluted city into a positive force that allows the community to regain its self-confidence and pride. In this respect, the initiatives taken by the Kumamoto prefectural government and Minamata City’s mayor were decisive. Instead of asking for the moon, citizens need to catalog what they already have (community resource maps) and disseminate information. In the case of Minamata, the 21-category waste separation project has had an educational effect on its citizens: it is an initiative that eliminates the "polluted city” stigma associated with Minamata and helps people regain their civic pride. Furthermore, a strategy is needed to change the detrimental polluted-city legacy into an eco-tourism resource. This relates to the framework condition of the political system for capacity building.

Finally, these strategies, and the people who employ them, make it possible for Minamata to no longer 
be a one-company town and, as a result, to revitalize other city industries. This relates to the economic and technological conditions for capacity building. As part of its efforts to wean Minamata's economy off dependence on Chisso and to change the mechanism that caused Minamata disease, the city is implementing practical steps to develop itself into a sustainable city of industry and culture. Specific efforts include the Eco-town strategy and similar strategies to diversify the industrial structure, revitalizing primary industries and creating tertiary industries that support the elderly and the handicapped. Breaking away from its role as a company town that is economically and politically dependent on a few big corporations, and building a more diverse set of industries, is a challenge for all cities that aim to achieve truly affluent and safe living. Instead of seeing cities and local areas as isolated, it is important to have strategies that seek a harmonious balance between the surrounding natural environment and farming and fishing, while actively incorporating new technologies suited to a region's purposes. These strategies will play a pivotal role in conceiving and achieving 21st-century urban renewal.

The environmental restoration strategy for Minamata City, known around the world as a pollution disaster area, shows us that, in order to make advantageous use of people and resources for urban renewal, it is necessary to discern one's local strengths and then, having encouraged citizens to participate, to change one's way of thinking without being fettered by the past.

Acknowledgments I am grateful for the support of Kumamoto Prefecture (Takayuki Kumamoto), the City of Minamata (Tetsuro Yoshimoto), Masazumi Yoshii, Soshia (Kunio Endo), Hotto House (Takeko Kato), Chisso Minamata Factory, Act-be Recycling, Tanaka Company, RBS, Replatech, Shin’ichiro Kogata, Kiyota Kogata, Toshio Yoshinaga, Asari Ori, Hajime Sugimoto, Kiyokata Maruta, Toru Sawahata, and Haruyo Yoshida.

\section{References}

Discussion Group on Minamata Disease, Ministry of the Environment (2006) Proposal of discussion group on Minamata disease (in Japanese)

Harada M (1972) Minamata disease (in Japanese). Iwanami Shoten, Tokyo

Ja“nicke M (2002) The political system’s capacity for environmental policy. In: Weidner H, Ja“nicke M (eds) Capacity building in national environmental policy. Springer, Berlin

Heidelberg New York, pp 1-18 Miyamoto K (ed) (1977) Restoration of a polluted city: Minamata (in Japanese). Chikuma Shobo

Yoshida F, Yoshida H (2004) How to face environmental risk: the case of Minamata disease (in Japanese). Shiso (Thought) 963:102-121

Yoshii M (2003) From polluted city to environmental city (in Japanese). Lecture on 13 December 2003, Kumamoto 